
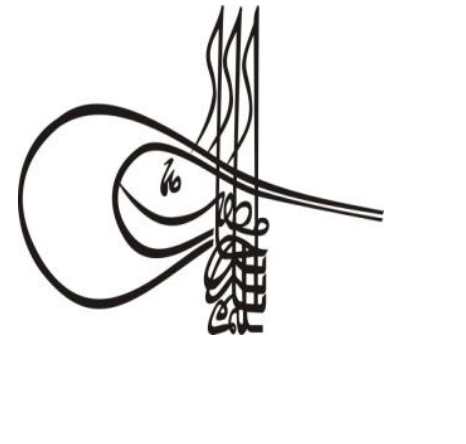

Received/Geliş: 01.10 .2019

Go Report Dates/Rapor Tarihleri: Referee 1 (11.12.2019)-Referee 2 (10.12.2019)

\section{Turkish Studies \\ Language and Literature \\ Volume 14 Issue 4, 2019, p. 2003-2012 \\ DOI: 10.29228/TurkishStudies.38204 \\ ISSN: 2667-5641 \\ Skopje/MACEDONIA-Ankara/TURKEY

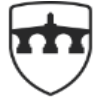 \\ INTERNATIONAL \\ BALKAN \\ UNIVERSITY \\ EXCELLENCE FOR THE FUTURE IBU.EDU.MK}

Research Article / Araştırma Makalesi

Article Info/Makale Bilgisi

VAccepted/Kabul: 20.12.2019

This article was checked by iThenticate.

\title{
KIRK VEZİR HİKÂYELERİNDE METİN İÇERİK KARŞILAŞTIRMASI (İSTANBUL VE KONYA NỬSHALARI)*
}

\author{
Serhat KÜÇÜK $K^{* *}$ - Yunus Alperen ÖNCEL $L^{* * *}$ - Cansu PANCAR ${ }^{* * * *}$
}

\begin{abstract}
öz
Kırk Vezir Hikâyeleri, Türk Edebiyatı'ndaki doğu anlatı geleneğini temsil etmesi bakımından oldukça özgün bir eserdir. Kurmaca ve gerçeğin bir arada bulunduğu hikâyelerde, doğu insanının anlatım zarafeti, hikemi düşünce tarzı ile vücut bulmuştur. Kırk Vezir Hikâyelerinin dünya ve Türkiye'deki çeşitli kütüphanelerde yetmişten fazla nüshas1 mevcuttur. Elimizde bulunan yazma nüsha Konya Kütüphanesi'nde şu kayıtla yer almaktadır D.K.By 865/1-3, 104 Yk. , 15 str. , 200x145-170x100 mm Harekeli Nesih, 1063 H. Konusu: İslam dini akâidi, kelam, peygamber inanc1 178 varaktır. Yazma üç bölümden oluşmaktadır. 108a'ya kadar Kitab-1 Güzîde Akâid'ül İslâm yer almaktadır. Bu eser üzerine Dr. Serhat KÜÇÜK 'ün giriş-metin-sözlük şeklinde yayınlanmış bir çalışması bulunmaktadır. 108b'den 122a'ya kadar Kıssa-i İblis yer almaktadır. Bu yazma üzerinde Dr. Serhat KÜÇÜK 'ün henüz yayınlanmamış bir çalışması bulunmaktadır. 122a'dan 178b'ye kadar Şah Hikâyeleri yer almaktadır. Bu eser üzerine de halen sürdürülen bir çalışma mevcuttur. Bu hikâyelerde ilk eşini kaybeden şahın, yeni bir kadınla evlenmesi, bu kadının şahın oğluna iftira atması sonucu gelişen olaylar konu edilir. Şahın yeni eşi şehzadenin öldürülmesi için şaha her gece bir hikâye anlatır, şehzadenin ölümüne karşı çıkan vezirlerde şaha her sabah başka bir hikâye anlatır ve bu hikâyeler kırk gün boyunca devam eder. Bu çalışmada, elimizde bulunan yazma Konya
\end{abstract}

\footnotetext{
* Bu çalışma, 5. Uluslararası Sosyal Bilimler Kongresi’nde (INCSOS 2019) bildiri olarak sunulan 'Kırk Vezir Hikâyelerinde Metin İçerik Karşılaştırması (İstanbul ve Konya Nüshaları)' başlıklı bildirinin genişletilmiş biçimidir.

\section{** ID Dr. Öğr. Üyesi Kocaeli Üniversitesi, E-posta: serhatkucuk19@gmail.com}

Kocaeli Üniversitesi Eğitim Fakültesi, Türkçe ve Sosyal Bilimler Eğitimi Bölümü, Lisans Öğrencisi, E-posta: yunusalperen97@ hotmail.com 
nüshası ile İstanbul Topkapı Sarayı Revan Kitaplığ1 1080 numara ile kayıtlı nüshanın içerik bakımından karşılaştırması yapılmıştır. Ortaya çıkan sonuçlar tasnif edilmeye çalışılmıştır.

Anahtar Kelimeler: Kırk Vezir Hikâyeleri, Şah Hikâyeleri, Eski Anadolu Türkçesi, Anlatı Geleneği, Çerçeve Hikâye.

\title{
COMPARING ISTANBUL AND KONYA COPIES OF KIRK VEZIR STORIES
}

\begin{abstract}
Kırk Vezir Stories is a pretty original literary work in terms of representing east narrative tradition in Turkish Literature. Narration grace of eastern man comes into existence with a didactic turn of mind in related stories in which fiction and reality collocate. Kırk Vezir Stories have more than seventy copies in various libraries in Turkey and the world. Our available copy is recorded in Konya Library as follows; D.K.By 865/1-3, 104 Yk. , 15 str. , 200x145-170x100 mm Naskh with Vowel Point, 1063 H. Subject: Fundamental Principles of Islam, word, prophet belief, 178 leaves. The text consists of three parts. There is seen 'Kitab-1 Güzîde Akâid'ül İslâm' till 108a. Dr. Serhat KÜÇÜK has a work that was published as 'introduction-text-dictionary' on this text. There also is 'Kissa-i İblis' from 108b to 122a. Dr. Serhat KÜÇÜK has a not yet published work on this writing. There are Shah Stories from 122a to $178 \mathrm{~b}$. We can also talk about an ongoing study in this writing. These stories treat events that actualized the marriage of Shah who lost his first wife and the thing that developed as the result of slander of Shah's new wife to Shah's son. Every night, Shah's new wife told a story to Shah to kill his son. On the other hand, viziers who challenged to be killed him told stories to Shah every morning; related stories continued for forty days. This paper compared our available Konya Library copy and the 108 numbered copy of İstanbul Topkap1 Palace Revan Library. It has endeavored to classified the results.
\end{abstract}

\section{STRUCTURED ABSTRACT}

It is known that Kirk Vezir Stories that are one of the prose examples of 15 th century were translated by Ahmed-i Misri from a text called 'Hikayet-i Erbain-i Subh-u Mesa' whose Arabic original is lost; copies were only submitted to II. Murat. Then the text was written by the Sultan's son again and the new copies were presented to both II.Murat and II.Mehmet (Gibb, 1886;1934;Birinci 2012).

The subject of Kirk Vezir Stories which are one of the most remarkable samples of East Narrative Tradition and Frame Story is as follow; Sultan whose wife died married a new woman; this new woman fell in low with Sultan's son. The son did not reciprocate her love. The stepmother who could not be loved in return nursed a grievance to Sultan's son; she tried to get him killed by slandering. This new wife told stories to Shah about being boys unfaithful and scapegrace. Sultan's son could not respond to those slanders because of his dreams and

Turkish Studies - Language and Literature

Volume 14 Issue 4, 2019 
suggestions of his teacher. Forty viziers of shah did nit believe in the lies and slanders of the new wife while the Shah was persuaded to get his son killed and send message to his executioner. In this direction, viziers advice and told stories to Shah about lies and fictions of the woman for forty mornings. Stories of new wife and viziers continued for forty days and forty nights. Teacher of sultan's son allowed him to talk at the end of forty days. Thereupon, sultan's son told his father that the stepmother falls in love with himself; he can take the place of him if he requites her love; the reason for slanders is his rejection. Sultan's son was in the clear by the testimony of viziers and odalisques. Then Shah punished his wife and get her killed.

Kirk Vezir Stories have approximately seventy copies in various regions of Turkey and the world. There are studies on related copies. Konya Copy that is the reference of this paper is recorded in Konya Library as follows; Muhammed b. Bâli, Kitâb-1 Güzide 104 Yk. , 13str. , 200x145-170x100 mm D. K. By 865/1-3 Naskh with Vowel Point, 1063 H. Subject: Fundamental Principles of Islam, word, prophet belief, 178 leaves. Dr. Serhat KÜÇÜK has a work that was published as 'introduction-text-dictionary' on this text. There can be seen 'Kissa-i İblis' from $108 \mathrm{~b}$ to $122 \mathrm{a}$. Dr. Serhat KÜÇÜK has a not yet published work on this writing. There are Shah Stories from 122a to 178b. We can also talk about an ongoing study in this writing.

In this study, similar stories in 1080 numbered copy in İstanbul Topkap1 Revan Library and the copy in Konya Library were compared in terms of content. Differences in compared stories were collected under names and actions. Then, the differences on storyline were discussed under the title of actions; again, the differences in personality and nomenclatures, places, numbers, animals, food and drinks, objects, slogans were scrutinized under the title of names.

In conclusion, stories in İstanbul Topkapı Revan copy and Konya copy were compared in terms of content. Thirty-three of compared stories is similar ones as well as there are differences in proposition-nodesolution parts. Node and solution parts are the same while there is seen that introduction parts of some of the compared studies are completely different. Introduction and proposition parts of some of the related studies are the same while the node parts are completely different. Moreover, Konya Copy's stories ("Hz. Davut and Urya Bey, Terzinin Karıs1 (Wife of Tailor), Türk Çiftçi ile Karısı (Turkish Farmer and his Wife), Çırtıboğacık, Şeyh and Abdal, Şah and Nedimi, Bağban with Uğnı, Çengi Dilaram, Koyun ile Kuzu (Lamb with Sheep), Bağdatlı Hoca'nın Oğlu (Son of Teacher from Bagdad), Vezirin Oğlu (Vizier's Son), İhanetin Bedeli (Price of Betrayal), Cain and Abel" ) which are entitled by us could not be found in İstanbul Topkapı Revan copy. Our studies on these studies in Konya copy have continued.

Kirk Vezir Stories is one of the representatives of East Narrative Tradition such as Simbadnameler, Kutadgu Bilig, Binbir Gece Masallar1 (1001 Arabian Nights), Yusuf ile Züleyha. In 1001 Arabian Nights, the hostility of Şehriyar who was betrayed by his wife is told; similarly, Scheherazade told stories to Şehriyar. This side of 1001 Arabian Nights shows similarity to Kırk Vezir Stories. Again, slanders of the stepmother 
who could not be loved in return and also her efforts to get killed her stepson evoke the story of Yusuf and Züleyha.

Anecdotes in stories guide readers to goodness, merit, wisdom, and morals; related anecdotes also are didactical and advisory. Prophet, four great caliphs and fundamental principles of Islam were utilized in stories of viziers. In these stories, Sufistic events such as suffering, retreating, fasting for forty days, circumambulating the marquee for seven times were told. In the meantime, stories inform us about models of living, traditions, and beliefs of people. We can deduce relating to the social life of citizens when the stories are analyzed in general. There can be read many things on both trade, education and the birds and the bees. Social events like clothing caftan to viziers by the Shah; throwing ring; to baste the mustache; obeying to mother and father; using mourning dress are expressed in related stories. Again, in stories, characteristics which should be in statesmen can be seen in these texts. Concerning suggestions, statesmen should be patient, brave and reliable; manage the crisis well; evaluate the background of each thing in depth. Different disciplines such as management sciences, folk literature, sociology, and folklore need to make investigations on these stories.

Keywords: Kırk Vezir Stories, Şah Stories, Old Anatolian Turkish, Narrative Tradition, Frame Story.

\section{Giriş}

Elimizde bulunan yazma nüsha Konya Kütüphanesinde şu kayıtla yer almaktadır: Muhammed b. Bâli, Kitâb-1 Güzide 104 Yk. , 13str. , 200x145-170x100 mm D. K. By 865/1-3, Harekeli Nesih, 1063 H. Konusu: İslam dini akâidi, kelam, peygamber inanc1 178 varaktır. Yazma üç bölümden oluşmaktadır. 108a'ya kadar Kitab-1 Güzîde Akâid'ül İslâm yer almaktadır. Bu eser üzerine Dr. Serhat KÜÇÜK'ün giriş-metin-sözlük şeklinde yayınlanmış bir çalışması bulunmaktadır. 108b'den 122a'ya kadar Kıssa-i İblis yer almaktadır. Bu yazma üzerinde Dr. Serhat KÜÇÜK'ün henüz yayınlanmamış bir çalışması bulunmaktadır. 122a'dan 178b'ye kadar Şah Hikâyeleri yer almaktadır. Bu eser üzerine de halen sürdürülen bir çalışma mevcuttur.

15.yy nesir örneklerinden biri olan Kırk Vezir Hikâyelerinin Arapça aslı kayıp olan Hikâyeti Erbain-i Subh-u Mesa adlı bir eserden Ahmed-i Mısri tarafından çevrildiği ve bu şekilde çoğaltılan nüshaların yalnız II. Murat'a sunulduğu bilinmektedir. Daha sonra eser şehzade tarafindan yeniden kaleme alınmış ve bu şekilde yazılan nüshalar ise hem II. Murat'a hem de II. Mehmet'e takdim edilmiştir. (Gibb,1886;1934;Birinci 2012)

Doğu anlatı geleneğinin edebiyatımızdaki en güzel örneklerinden olan Kırk Vezir Hikâyelerinin dünyanın farklı kütüphanelerinde yetmişten fazla nüshası tespit edilmiştir. Hikâyeler üzerine yüksek lisans ve doktora çalışmaları mevcuttur. Çalışmanın referansı olan Konya nüshası 49 hikâyeden oluşmaktadır. Nüshanın bazı varaklarında eksiklikler ve okunamayan kısımlar mevcuttur. Nüshada yer alan hikâyeler içeriklerine göre tarafimızdan isimlendirilmiştir.

İstanbul Topkapı Revan Nüshası ve Konya Nüshasında yer alan benzer hikâyeler içerikleri bakımından karşılaştırılmıştır. Hikâyelerin karşılaştırılmasında, adlar ve eylemler olarak iki ana başlıkta sınıflandırılmıştır. Adlar başlığı altında; şahıs ve unvanlar, mekânlar, sayılar, hayvanlar, yiyecek ve içecekler, nesneler, kalıp sözler ile ilgili farklılıklar; eylemler başlığı altında ise olay örgüsü ile ilgili farklılıklar ele alınmıştır. 
Çalışmada Kırk Vezir Hikâyeleri İstanbul Topkapı Revan Nüshası ile Konya Nüshası karşılaştırılarak, iki yazma eserde bulunan benzer hikâyelerin içeriği günümüz Türkçesine çevrilerek belirtilen tasnif doğrultusunda incelenmiştir.

\section{Adlar}

\section{1. Şahıslar ve Unvanlar ile İlgili Farklııklar}

Horasanlı Derviş Hikâyesinde Konya metninde başkahraman için "derviş", İstanbul metninde "yoksul adam" unvanı kullanılmıştır.

Horasanlı Derviş Hikâyesinde Konya metninde hikâyeyi anlatan kişi "hatun" olarak İstanbul metninde "kadın efendi" unvanı kullanılmıştır.

Bezirgânın Çocuklarına Mirası Hikâyesinde, Konya metninde bezirgân için başka unvanlar yanında "hoca" unvanı da kullanılırken İstanbul metninde bezirgân için herhangi bir unvan yoktur.

Zâhid ile Şeytan Hikâyesinde Konya metninde başkahraman "Zâhid Sıysa" olarak isimlendirilirken, İstanbul metninde "Bersis" olarak isimlendirilmiştir.

Zâhid ile Şeytan Hikâyesinde Konya metninde "Ebyaz" isimli şeytanın oğlu yokken İstanbul metninde şeytanın bu isimde bir oğlu vardır.

Hz. Havva ile Âdem Hikâyesinde Konya metninde şeytanın oğlu için "Hannas" adı kullanılırken İstanbul metninde şeytanın oğlu için "oğlak" ifadesi de kullanılmıştır.

Halkın Diline Düşmek Hikâyesinde Konya metninde kişi "bostancı" diye anlatılmazken İstanbul metninde "bostancı" olarak adlandırılmıştır.

Halkın Diline Düşmek Hikâyesinde Konya metninde bostancı için “donuz" ifadesi kullanılmıştır. İstanbul metninde ise "sübyancı" ifadesi kullanılmıştır.

Halkın Diline Düşmek Hikâyesinde Konya metninde bostancı için başka unvanların yanında "pir" unvanı da kullanılırken İstanbul metninde başka hiçbir unvan kullanılmayıp yalnız "yaşlı adam" unvanı kullanılmıştır.

Bengiler Hikâyesinde Konya metninde kişiler "yiğitler" İstanbul metninde “esrarkeşler" olarak adlandırılmıştır.

Halid bin Velid ile Rahip Hikâyesinde Konya metninde "sahübümüz" İstanbul metninde “önderimiz” şeklinde adlandırılmıştır.

Halid bin Velid ile Rahip Hikâyesinde Konya metninde Ebubekir Siddık ile Halid bin Velid kıyaslanmıştır, İstanbul metninde böyle bir kıyaslama yoktur.

Halid bin Velid ile Rahip Hikâyesinde Konya metninde Ömer bin Hattab ile Halid bin Velid kıyaslanmıştır, İstanbul metninde böyle bir kıyaslama yoktur.Konya metninde Halid bin Velid ile Osman ibn-i Affan kıyaslanmıştır, İstanbul metninde böyle bir kıyaslama yoktur.

Konya metninde Doğan Kuşu Hikâyesinde "Seyyid Ahmet Oğullarından Seyyid Rükneddin derlerdi bir Seyyid Ahmet Oğlu vardı" şeklinde anlatıma başlanırken İstanbul metninde bu kişi "şah" olarak geçmektedir.

Bezirgân Cariye ve Maymunu Hikâyesinde Konya metninde bezirgân için diğer unvanların yanında "hoca" unvanı da kullanılırken İstanbul metninde bu unvan kullanılmamıştır.

Bezirgânın Sonu Hikâyesinde; İstanbul metninde "yılan" cin padişahının kızıyım derken Konya metninde sadece cin kızıyım demiştir. 
Daletü'l Muhtal Hikâyesinde Konya metninde şahın yanında uyuyan kişi "oğlan” olarak adlandırılmış, İstanbul metninde ise "köle" olarak adlandırılmıştır.

Arap Beyi Hikâyesinde İstanbul metninde şahın yanına gelen kişi Emir Sarım olarak geçerken Konya metninde Emir Semhul olarak geçer. anlatılmıştır.

Derviş ve Haramiler Hikâyesinde Konya metninde "yiğit" İstanbul metninde "adam” olarak

Mısır Sultanı ve Vezirleri Hikâyesinde Konya metninde şahın oğlu diye anlatılırken İstanbul metninde yeni vezir diye bahsedilmiştir.

\subsection{Mekân ile İlgili Farklılıklar}

Bezirgânın Çocuklarına Mirası Hikâyesinde Konya metninde ikinci oğlanın nereye gittiği belli değilken İstanbul metninde "denize açıllyor" şeklinde belirtilmiştir.

Nuh Peygamber ve Oğlu Hikâyesinde Konya metninde helak oldukları yer için "sırçadan ev", İstanbul metninde ise "sırçadan kubbe" denilmiştir.

Bezirgân ve Oğlu Hikâyesinde Konya metninde şehir olarak Uzla şehri geçerken İstanbul metninde ise Urfa şehri geçmektedir.

Öğüt Veren Derviş Hikâyesinde Konya metninde şah seyrana çıkıp yürürken İstanbul metninde avdan dönmektedir.

Sultan Alâeddin ile Deli Bir Oğlan Hikâyesinde Konya metninde herhangi bir şehir ismi geçmezken İstanbul metninde Konya şehrinin ismi geçmektedir.

Bengiler Hikâyesinde Konya metninde mekân olarak "karhana" İstanbul metninde "kullanılmayan bir ev" olarak kullanılmıştır.

Hoca ile Kandilleri Parçalayan Oğlu Hikâyesinde Konya metninde "Dımaşk' da bir hocanın oğlu vardı" şeklinde anlatılırken İstanbul metninde "cihan sarayında ulu bir padişahın oğlu vardı şeklinde anlatılmaktadır.

Derviş ve Haramiler Hikâyesinde Konya metninde derviş $1 \mathrm{ss} ı z$ bir yere gidiyor ve bir kervansaraya varıyor, kervansarayın yanında bir kaba ağaç ve latif bir pınar vardır diye anlatılırken İstanbul metninde bu durum anlatılmamıştır.

\subsection{Sayılar ile İlgili Farklılıklar}

Bezirgânın Çocuklarına Mirası Hikâyesinde Konya metninde çocukların yaşayacağı süre olarak "artuk eksik altmış yetmiş yıl" olarak verilirken İstanbul metninde "yüzer yll" olarak verilmiştir.

Bezirgânın Çocuklarına Mirası Konya metninde oğlanlara verilecek para olarak "iki bin akçe", İstanbul metninde "bin akçe" belirtilmiştir.

Zâhid ile Şeytan Hikâyesinde Konya metninde Zâhid'in yüz y1l boyunca halktan uzak bir hücrede ibadet ettiği anlatılmazken İstanbul metninde bu durum anlatılmıştır.

Zâhid ile Şeytan Hikâyesinde Konya metninde şeyhin yetmiş yıl ibadet ettikten sonra imansız gittiği anlatılırken İstanbul metninde bu olay anlatılmamıştır.

Nuh Peygamber ve Oğlu Hikâyesinde Konya metninde "suyun yüksekliği en yüksek dağları bile aştı kırk arşın yukarıya kadar ulaştı" ifadesi yokken İstanbul metninde bu olay anlatılmıştır. 
Kayser-i Rum ile Hasan Basri Hikâyesinde Konya metninde çadırın çevresini yedi kez dolaşırlarken İstanbul metninde "üç kez dolaştık şeklinde" anlatılmıştır.

Öğüt Veren Derviş Hikâyesinde Konya metninde dervişin nasihati için şah "bin kızıl değil canlar eder" derken, İstanbul metninde "bin altın değil yüz bin altın değerlidir” demiştir.

Sultan Alâeddin ve Deli Bir Oğlan Hikâyesinde Konya metninde deli "falan gündür buradayım" derken İstanbul metninde deli "yirmi üç günden beri buradayım" demiştir.

Halid bin Velid ile Rahip Hikâyesinde Konya metninde ana rahmindeki çocuk dört aydan dokuz aya kadar yemez içmez olarak anlatılmıştır, İstanbul metninde bu süreler verilmemiştir.

Her Şeye İtiraz Eden Çocuk Hikâyesinde Konya metninde annenin çocuğa verdiği yemek on kişiye yeterdi diye anlatılmıştır. İstanbul metninde sadece büyük bir tencere yemek verdi olarak anlatılmıştır.

\subsection{Hayvanlar ile İlgili Farkhılıklar}

Hz. Havva ile Âdem Hikâyesinde Konya metninde şeytan oğlunu oğlak suretine koyması olayı anlatılmamışken İstanbul metninde bu durum anlatılmıştır.

Bengiler Hikâyesinde Konya metninde adamın sakalına, eteğine, dudağına bulaşan yemeği at yalamıştır, İstanbul metninde ise aç bir köpek yalamıştır.

Konstantiniye Tekfuru Hikâyesinde Konya metninde fareler için yardım teklifini İbn-i Sina yaparken İstanbul metninde padişah yardım istemiştir.

Bezirgân Cariye ve Maymunu Hikâyesinde Konya metninde bezirgân bir maymun satın aldı diye anlatılırken İstanbul metninde evde bir maymunu vardı diye anlatılmıştır.

Bezirgânın Sonu Hikâyesinde İstanbul metninde oğlanın satın aldığı yılanın rengi beyazdır, Konya metninde renk belirtilmemiştir.

Bezirgânın Sonu Hikâyesinde İstanbul metninde genç oğlanın hem kedisi hem köpeği vardır ancak Konya metninde yalnızca kedisi vardır diye anlatılmıştır.

Pire ile Süleyman Peygamber Hikâyesinde -Konya metninde iki pire Süleyman katına gidiyor şeklinde anlatılırken İstanbul metninde birçok pire şeklinde anlatılmıştır.

Padişah ve Vezirin Hikâyesi Konya metninde ölü kaz getirdiler şeklinde anlatılırken İstanbul metninde boğazlanmış kaz getirdiler olarak anlatılmıştır.

Çözüm Hikâyesinde Konya metninde kör aygır ve kadını bir sahraya çıkarıp kadının saçlarını kör aygırın kuyruğuna bağlayıp helak olması olayı anlatılırken İstanbul metninde yaban eşeğini ve kadının siyaset meydanına getirilip kadının eşek üzerine bindirilip ayaklarını kuyruğuna bağlayıp helak olması şeklinde anlatılmıştır.

\subsection{Yiyecek-İçecekler ile İlgili Farklılıklar}

Horasanlı Derviş Hikâyesinde Konya metninde yedikleri yemekler arasında tatlı yokken İstanbul metninde "tatlı" vardır.

Bezirgân Cariye ve Maymunu Hikâyesinde Konya metninde kazan su ile doldurulup kaynatılırken İstanbul metninde süt ile doldurulup kaynatılır.

Şahın Kıskanılan Sohbet Arkadaşı Hikâyesinde Konya metninde nedimin hasudlarından birisi Sarımsaklı Tutmac pişirdi diye anlatılırken İstanbul metninde Tatar Böreği olarak anlatılmıştır. 


\subsection{Nesneler ile İlgili Farklılıklar}

Horasanlı Derviş Hikâyesinde Konya metninde bıyığa sürülen "yağ", İstanbul metninde "kuyruk yağı" olarak belirtilmiştir.

Öğüt Veren Derviş Hikâyesinde Konya metninde şahın damarından kan almak için kullanılan neşter hazine neşteridir ancak İstanbul metninde "hazineye ait bir neşter değildir" olarak geçmektedir.

Sultan Alâeddin ile Deli Bir Oğlan Hikâyesinde Konya metninde "büyük bıçak" olarak isimlendirilirken İstanbul metninde "bıçak" olarak adlandırılmıştır.

Bezirgânın Sonu Hikâyesinde Konya metninde oğlan ipin ucunu kendini asmak için bir ağaca bağlar İstanbul metninde ise evdeki halkaya bağlar.

Âmâ Hikâyesinde Konya metninde halifenin hokkası kaybolurken İstanbul metninde mücevher ve değerli taşlarla dolu kutusu kaybolmuştur.

\subsection{Kalıp Sözler ile İlgili Farklııklar}

Bezirgânın Çocuklarına Mirası Hikâyesinde Konya metninde şah “Allah-u Ekber” demezken İstanbul metninde demiştir.

Bezirgânın Çocuklarına Mirası Hikâyesinde Konya metninde "oğlan kısmında akıl namus olmaz" denilmişken İstanbul metninde "oğlanlarda arz namus dost düşman gayreti yoktur" denilmiştir.

Vezirin Oğluna Âşık Olan Padişah Hikâyesinde Konya metninde şahın oğlan için söylediği övgülerden "hayat suyum" ifadesi yoktur bu ifade İstanbul metninde vardır.

Vezirin Oğluna Âşık Olan Padişah Hikâyesinde Konya metninde şah vezirin oğlu için "Kim yarı yoktur canı yoktur / Issız il gibidür sultanı yoktur" beyitini okumuştur İstanbul metninde bu yoktur.

Halkın Diline Düşmek Hikâyesinde Konya metninde bostancı için "donuz" ifadesi kullanılmıştır. İstanbul metninde ise "sübyancı" ifadesi kullanılmıştır.

Öğüt Veren Derviş Hikâyesinde Konya metninde şah müzeyyine "seni sam sevenlere yediririm "şeklinde anlatılmışken, İstanbul metninde "boynunu vurdururum" olarak anlatılmıştır.

Sultan Alaaddin ile Deli Bir Oğlan Hikâyesinde Konya metninde deli şaha "bre rrs" olarak hitap etmiştir İstanbul metninde "pezevenk" olarak hitap etmiştir.

Sultan Alaaddin ile Deli Bir Oğlan Hikâyesinde Konya metninde “Tengri” İstanbul metninde “Allah” kullanılmıştır.

Bengiler Hikâyesinde İstanbul metninde "dost bile olsa kafası iyiyse düşman işi yapabilir" şeklinde bir atasözüne yer verilirken Konya metninde buna yer verilmemiştir.

Halid bin Velid ile Rahip Hikâyesinde Konya metninde "ayıp olmaya kim ve fevka ilmün alemindür" sözü İstanbul metninde kullanılmamıştır.

Bezirgânın Sonu Hikâyesinde İstanbul metninde oğlanı cadılar büyü gücüyle öldürür Konya metninde ise "siyavuş hun gibi kanı döküldü" şeklinde anlatılır.

Çözüm Hikâyesinde İstanbul metninde halk arasında yayılmış olan "seni eşekte göreyim" sözü varken Konya metninde bu söylem yoktur. 


\section{Eylemler}

\subsection{Olaylar ile İlgili Farklılıklar}

Vezirin Oğluna Âşık Olan Padişah Hikâyesinde Konya metninde vezir oğlanı çiçek gibi alıp şahın halvetine götürüyor, İstanbul metninde bu olay anlatılmamıştır.

Zâhid ile Şeytan Hikâyesinde Konya metninde şahın kızının içine cin girmesi olayı anlatılmamışken İstanbul metninde bu olay anlatılmıştır.

Hz. Havva ile Âdem Hikâyesinde İstanbul metninde Hz. Âdem'in oğlağı parça parça etmesi ve şeytan yüzünden Hz. Havva'ya vurması olayı anlatılırken Konya metninde bu olay yoktur.

Sultan Alaaddin ile Deli Bir Oğlan Hikâyesinde -İstanbul metninde şahın elini yüzünü yıkaması, sarayına gitmesi ve bir daha asla akıl hastanesine gitmeyeceği anlatılmışken Konya metninde bu anlatılmamıştır.

Bengiler Hikâyesinde Konya metninde adamın sakalına, eteğine, dudağına bulaşan yemeği at yalamıştır, İstanbul metninde ise aç bir köpek yalamıştır.

Halid bin Velid ile Rahip Hikâyesinde İstanbul metninde Halid bin Velid ve rahip Resul'ün huzuruna gelip hizmet ederler, Konya metninde bu kısım anlatılmamıştır.

Konstantiniye Tekfuru Hikâyesinde Konya metninde "Ebu Ali dümbeği eline aldı çala çala gitti” şeklinde anlatılırken İstanbul metninde bu kısım anlatılmamıştır.

Bezirgân, Cariye ve Maymunu Hikâyesinde İstanbul metninde cariye maymun ile çiftleşmek istemeyip bezirgâna tepki gösteriyor, bezirgân ona özgürlüğünü vereceğini söyleyince cariye kabul ediyor diye anlatılırken bu kısım Konya metninde anlatılmamıştır.

Şahın Kıskanılan Sohbet Arkadaşı Hikâyesinde İstanbul metninde padişahın kılık değiştirme olayı anlatılırken Konya metninde bu anlatılmamıştır.

Hoca ile Kandilleri Parçalayan Oğlu Hikâyesinde Konya metninde oğlanın vurduğu kandillerin bin pare olduğu anlatılırken İstanbul metninde birçok kandil kırıllyor şeklinde anlatılmıştır.

Daletül Muhtal Hikâyesinde İstanbul metninde hikâyenin başında anlatılan alışveriş olayı Konya metninde yoktur.

Âmâ Hikâyesinde Konya metninde halife kör adama okkanın içindekiler ile ilgili sorular sormuştur İstanbul metninde ise kör kendisi anlatmıştır.

Derviş ve Haramiler Hikâyesinde İstanbul metninde elleri bağlı genci direğe bağl1yorlar ve ateş yakıp yemek pişiriyorlar şeklinde anlatılırken Konya metninde bu olay anlatılmamıştır.

Mısır Sultanı ve Vezirleri Hikâyesinde Konya metninde şah ve nedimin tahıl içine gizlendikleri anlatılırken İstanbul metninde bu olay anlatılmamıştır.

İstanbul metninde kadının cezalandırılması ile şah ve vezirler müzik eşliğinde yiyip içtiler zevk ve sefa sürdüler şeklinde olaylar anlatılırken Konya metninde vezirler kırk gün giydikleri matem tonu giysilerini çıkarıp şahane hilatler giymişler, şarap ve kebap ziyafeti vermişler şeklinde anlatılmıştır.

\section{Sonuç}

İstanbul Topkapı Revan Nüshası ve Konya Nüshasında bulunan hikâyeler içerik açısından karşılaştırıldığında karşılaştırılan hikâyelerden otuz üçü benzer hikâyeler olmakla birlikte bu hikâyelerin serim-düğüm-çözüm kısımlarında bazı farklılıklar tespit edilmiştir. Karşılaştırılan

\section{Turkish Studies - Language and Literature}

Volume 14 Issue 4, 2019 
hikâyelerin bazılarının giriş kısımlarının tamamen farklı olduğu görülürken düğüm ve çözüm kısımları aynıdır. Bazı hikâyelerin de giriş ve serim kısımları aynı iken düğüm kısımları tamamen farklıdır. Bu farklılıkların, alanla ilgili diğer araştırmacılar tarafından incelenerek üzerinde çalışma yapılması faydalı olacaktır. Ayrıca Konya Nüshasında bulunan ve tarafımızdan isimlendirilen "Hz. Davut ve Urya Bey, Terzinin Karısı, Türk Çiftçi ile Karısı, Çırtıboğacık, Şeyh ve Abdal, Şah ve Nedimi, Bağban ile Uğrı, Çengi Dilaram, Koyun ile Kuzu, Bağdatlı Hoca’nın Oğlu, Vezirin Oğlu, İhanetin Bedeli, Habil ile Kabil" hikâyeleri karşılaştırılan İstanbul Topkapı Revan nüshasında tespit edilememiştir. Konya Nüshasında tespit edilen bu hikâyeler üzerinde çalışmalarımız devam etmektedir.

Kırk Vezir Hikâyeleri Simbadnameler, Kutadgu Bilig, Binbir Gece Masalları, Yusuf ile Züleyha gibi doğu anlatı geleneğinin temsilcilerinden birisidir. Binbir Gece Masalları'nda da eşi kendisine ihanet eden Şehriyar'ın kadınlara düşmanlığı ve Şehrazat'ın Şehriyar'a hikâyeler anlatması durumu Kırk Vezir Hikâyeleri ile benzerlik göstermektedir. Yine şehzadeye duyduğu aşka karşılık bulamayan üvey annenin büyük bir korku ile iftiralar atması ve üvey oğlunu öldürtmeye çalışması Yusuf ile Züleyha hikâyesini hatırlatmaktadır.

Hikâyelerde bulunan kıssalar okuyanları iyiliğe, erdeme, akla, ahlaka yönlendirici, ders verici ve ögütleyici niteliktedir. Vezirlerin anlatmış olduğu hikâyelerde peygamberler ve dört halifeden, İslam dini akaitlerinden yararlanılmıştır. Yine bu hikâyelerde çile çekmek, inzivaya çekilmek, kırk gün oruç tutmak gibi tasavvufi olaylar da anlatılmıştır. Aynı zamanda hikâyeler insanların yaşayış biçimleri, gelenekleri, inançları hakkında bize bilgiler vermektedir. Genel olarak hikâyeler incelendiğinde kişilerin sosyal hayatına dair çıkarımlar yapılabilmektedir. Gerek ticaret, gerek eğitim gerekse kadın erkek ilişkileri üzerine birçok olay anlatılmaktadır. Yine hikâyelerde devlet yöneticilerinde olması gereken özellikler üzerinde durulmuştur. Bir yöneticinin sabırlı, cesur ve güvenilir olması; kriz durumunu iyi idare edebilmesi, her olayın arka planını detaylı olarak değerlendirmesi öğütlenmiştir. Hikâyeler üzerine yönetim bilimleri, sosyoloji ve folklor gibi farklı bilim dalları tarafından akademik çalışmalar yapılması faydalı sonuçlar ortaya çıkaracaktır.

\section{KAYNAKÇA}

Birinci, A.(2012) Kırk Vezir Hikâyeleri: İnceleme-Metin-Sözlük. Doktora tezi, İstanbul Üniversitesi. Erdem, M.D.(2018).Kırk Vezir Hikâyeleri. Ankara: Pruva Yayınları.

Kanar, M. (2011). Eski Anadolu Türkçesi Sözlüğü, İstanbul: Say Yayınları.

Kızıltan, M. (1991) Kırk Vezir Hikâyeleri (İnceleme) II Cilt. Doktora Tezi, İstanbul Üniversitesi.

Küçük, S. (2014). Kitâb-ı Güzîde Akâidü'l İslâm. İstanbul: Kesit Yayınları.

Özalp, N.A.(2014).Kırk Vezir Hikâyeleri. İstanbul: Kapı Yayınları.

Şeker, A. (2013) Şeyhzade- Kırk Vezir Hikâyeleri. Yüksek lisans tezi, Marmara Üniversitesi. 